\title{
A flor mais linda do mundo
}

Fan Shan

O autor, Francisco Mota (1946- ) é português, economista e apaixonado pela cozinha e a bebida dos povos. É um grande amigo meu há cerca de quinze anos. É uma pessoa muito sincera consigo e com os amigos, muito sensivel às coisas belas da vida diária. Tem, há anos uma coluna chamada "gastronomias" no semanario Avante, em que escreve histórias sobre temas gastronomicos dentro dos seus textos. Quando publicou este artigo, muitos dos seus amigos e leitores gostaram imenso e até choraram pelo amor tão puro e tão impossível entre um pássaro e uma flor. Normalmente lemos histórias de amor entre uma mulher e um homem, entre um leão e uma leoa, mas esta é uma história fora do habitual. Normalmente os pássaros não costumam apaixonar-se por flores. Aqui reside a originalidade desta história, que é realmente muito especial, diferente, sentimental. Triste e linda.

作者法兰西斯库莫塔（1946-）葡萄牙人，经济学家，酷爱烹饪 和各国红酒。是我 15 年的老朋友。他是个非常真诚的人, 无论对自己还 是对朋友。对生活非常敏感, 善于扑捉日常生活中的美好事物。多年来 在周刊《前进》报开设 “美食” 专栏。他的故事都会以美食为题, 当这 篇文字发表后, 在他的朋友和读者中反响强烈, 他们都十分喜欢, 乃至 被鸟对花儿如此纯洁又不可实现的爱情所感动地流泪。通常我们都读过 男人和女人之间的爱情故事, 公狮子和母狮子之间的爱情, 但这个故事 是个非常规的, 一般鸟儿是不会对花产生恋情的, 这正是本文的独创之 处。不可否认, 这是一篇非常特别, 非常不同, 充满感情, 悲伤又美丽 的故事。

\section{世界上最美的花儿}

伴你生, 我幸;

陪你死, 我命. 
失去爱, 册宁死,

唯有死, 留我爱.

---- 若阿金 - 萨比纳, 西班牙诗人, 作曲家和歌唱家

献给若阿金・萨比纳 (乌贝达, 马德里及世界各地)

他是只美丽的鸟。

羽毛几乎全黑, 有少许灰色, 胸部洁白如雪。

潒部红艳。

他飞起来像很多鱼那么快, 又有少数女士才具备的优雅。他即不 住在树上, 也没住在高山之巅, 而在一块岩石下筑了自己的巢, 既可御 寒和遮风避雨, 又可躲避风险, 是个相当不错的家。

这天一大早, 他就看到几米之外长着一棵植物, 上面有朵十分美 丽的花。他从未对花发生过兴趣, 也从未感到他小小的心脏心跳加速, 充满渴望。

他绕着花转了一圈, 又飞起来从各个角度鸟瞰。

他又飞的远一些, 变换着方向, 像每天那样高低盘旋。当返回时, 从远处遥望, 由远至近, 花朵也变得愈来愈大。他确信这是朵

最美丽的花儿

世上最美的花儿

这只鸟的生活从此改变, 他在花儿的周围度过的时间多起来。他愤 怒地不断攻击那些他认为会伤害花儿的大大小小的害虫; 下雨时, 不断 飞到花的上空, 极力张开翅膀, 为她挡住雨水的敲击。 那一边。

花儿也似乎在感谢他, 因为她逐渐地把脸转向了鸟所住的岩石的

鸟儿感到无比的幸福, 幸福得几近疯狂。他已经不再飞往远方, 而是以更多的时间高速地展翅高飞, 为的是之后能片刻滞留在花的上 方。为此他猛地直上云端, 然后下滑盘旋, 与花儿相近, 与花儿相望。

他期待着听到或看到他的朋友, 那朵

最美丽的花儿

世上最美的花儿

表现出的愉悦。

有一天, 当鸟儿用他的幸福填满天空的时候, 突然 2 声枪响, 随之 乌儿一头栽倒在花儿的身边, 右翅膀淌着鲜血。他强忍着伤痛终于回到 了家, 还依依不舍地注视着他的花儿。花儿似乎也感到了悲伤, 花辦低 
垂, 花容失色。

下雨了, 鸟儿飞不出去, 但这却让他有机会看着他的花, 那朵

最美丽的花儿

世上最美的花儿

身体也慢慢养好。

鸟突然吃了一惊, 他听到有人的脚步和说话的声音, 他们停在岩 石边了。当看到他们在花儿周围开始挖土的时候更为震惊, 为了不破坏 根茎, 他们挖得很深。然后他们带走了一切, 花儿, 土, 所有的一切。

他们带走花儿的那一刻, 好像花儿也望着他, 花的叶子在向他说 再见。也许是风声, 但鸟觉得就是她在说话。

他失去了他的朋友, 那朵

最美丽的花儿

世上最美的花儿。

鸟绝望了, 他想一定是人也看到了这株花儿的美丽。毫无疑问, 她现在住在富有的人家, 在一个价格不菲的瓷花盆里, 每天被人精心 的浇灌和照看着。

但是只有他们, 只有这富有的人家才能有看到她的快乐。没有其 他任何人了。 不动啊。

他想了很多去找她的计划, 但没有一个有可能实现。他连飞都飞

他难以入眠, 也休息不下, 几乎不吃不喝。身体一天天衰弱。

一天早晨, 他做了唯一能做的事: 忍着翅膀的巨疼离开了家, 踉 跟跑跑来到那些人留下的坑边, 让自己一头跌倒到坑底。

他感到阵阵剧痛, 慢慢让自己缓了一会儿后, 才开始寻找看看有 没有他们没带走的少许根荃。

找啊找啊，仅仅发现很小一点点残余的根须---至今他从未碰过 花儿一丁点, 他小心翼翼地用潒衔住那点根儿。一点点地清除了上面的 土, 又慢慢地慢慢地将它含在嘴里。他感到了她从没有给过他的吻, 那 么的美好!

合上双眼, 他入睡了, 带着满嘴的唇香, 它来自那朵

最美丽的花

世上最美的花儿。 


\section{A flor mais linda do mundo}

E morrer contigo, se te matam

E matar-me contigo, se tu morres,

Porque o amor quando não morre, mata

Porque amores que matam, nunca morrem.

(Joaquim Sabina, poeta, compositor e cantor espanhol)

Para Joaquim Sabina (Ubeda, Madrid e o resto do mundo)

Era um pássaro bonito.

Tinha as penas quase todas negras, algumas cinzentas e o peito branco. O bico era vermelho claro.

Voava com a rapidez de muitos peixes e a elegância dalgumas mulheres.

Não vivia numa árvore, nem no alto dum monte. Tinha feito o seu ninho debaixo duma pedra, protegido dos frios, das chuvas, dos ventos e dalguns perigos. Tinha uma boa casa.

Um dia, ao começar o dia, viu que a poucos metros crescia uma planta que tinha uma flor muito bonita. Nunca se tinha interessado por flores, nem nunca tinha sentido aquele bater apressado e ansioso, no seu pequeno coração.

Andou à sua volta e depois voou para a ver de todos os ângulos.

Voou para longe, mudando de direcção, subindo, descendo, como fazia todos os dias. Quando voltou, desde muito longe começou a ver a flor cada vez maior. Tinha a certeza de aquela era

A flor mais linda

A flor mais linda do mundo.

A vida do pássaro mudou. Ficava mais tempo à volta da flor. Atacava com fúria todos os bichos, grandes ou pequenos, que supunha poderiam fazer mal à flor. Quando chovia, voava sobre ela, com as asas muito abertas, para que a água não lhe batesse.

A flor parecia agradecer-lhe porque, a pouco e pouco, foi-se virando para a pedra onde ele vivia.

A felicidade do pássaro era enorme, quase louca. Já não se afastava para longe. Ficava muito tempo a voar com muita velocidade, para depois quase parar sobre ela. Subia na vertical e, de repente, deixava-se cair, para voltar a planar quando quase a tocava.

Tinha a esperança de ouvir ou ver, algum sinal de prazer da sua amiga

A flor mais linda

A flor mais linda do mundo.

Um dia quando o pássaro enchia o céu com a sua felicidade, ouviram-se dois tiros. Caiu ao lado da flor com sangue na asa direita. Conseguiu chegar a casa e aí ficou com a dor, mas sempre olhando para a sua flor. A flor também parecia mais triste com as folhas caídas e as pétalas descoloridas.

Choveu. O pássaro já não podia voar, mas foi melhorando vendo como ficava bonita

A flor mais linda

A flor mais linda do mundo.

O pássaro assustou-se quando ouviu passos e vozes de homens, que pararam junto da sua pedra. Assustou-se ainda mais quando viu que os homens cavavam à volta da sua flor. Cavavam fundo para não estragar as raízes e depois levaram tudo, flor, terra, tudo. 
Pareceu-lhe que quando a levavam, a flor olhava para ele e as folhas the diziam adeus. Talvez fosse o vento, mas o pássaro pensava que era ela.

Tinha perdido a sua amiga

A flor mais linda

A flor mais linda do mundo

No seu desespero, o pássaro pensou que os homens também tinham visto a beleza da flor. Certamente agora estaria numa casa rica, num vaso de porcelana cara, que a regariam todos os dias e que a tratariam com todo o cuidado.

Mas só eles, só essa família rica, podia ter o prazer de a ver. Mais ninguém...

Imaginou muitos planos para a encontrar, mas nenhum era possível. Nem sequer podia voar.

Não dormia, não descansava e quase não comia. Estava cada vez mais fraco.

Uma manhã, fez a única coisa que podia fazer. Saiu, ainda com muita dor na asa e arrastou-se até à cova que os homens tinham deixado. Quando chegou à borda deixou-se cair até ao fundo.

Doeu-lhe muito. Ficou parado um momento e começou a buscar na terra algum resto de raiz que os homens não tivessem levado.

Buscou muito, mas encontrou um resto pequenino - E ele, que nunca tinha tocado na flor, apanhou com o bico, com muito cuidado, aquela raiz.

Pouco a pouco foi-a limpando da terra. Muito devagar meteu-a na boca e sentiu o prazer do beijo que nunca the deu.

Fechou os olhos e adormeceu, com a boca cheia de sabor

Da flor mais linda

Da flor mais linda do mundo.

\section{Referência}

MOTA, Francisco. “A flor mais linda do mundo”. Jornal Avante! Edição 1809. Disponível em: http://www.avante.pt/pt/1809/argumentos/25512/ Acesso em 10 de fevereiro de 2013. 